\title{
Governamentalização da cidade: uma cartografia dos afetos, medo e esperança ${ }^{\star}$
}

\author{
Jeferson Camargo Taborda, (iD) I, $\star \star$ Anita Guazzelli Bernardes (iD II \\ ${ }^{I}$ Universidade Federal de Mato Grosso do Sul, Paranaíba, MS, Brasil \\ ${ }^{I I}$ Universidade Católica Dom Bosco, Campo Grande, MS, Brasil
}

\begin{abstract}
Resumo
O presente artigo faz uma reflexão teórica sobre a cidade a partir da noção de governamentalidade. Objetiva engendrar uma cartografia de linhas afetivas que aproximam matérias jornalísticas, canções de rap e publicidades do campo da segurança privada. O medo e a esperança são duas noções utilizadas para discutir os modos de circulação pela cidade e sua relação com os dispositivos de segurança. O medo, e especificamente o medo da morte, constitui um importante mecanismo de governo, pois, ao lembrar constantemente os sujeitos sobre sua finitude, um amplo mercado de segurança emerge. Já a esperança, afeto complementar do medo, é incitada enquanto uma estratégia precária de alegria, na medida em que se constitui como outra modalidade de sofrimento. Uma cartografia dos afetos fornece pistas sobre algumas formas de subjetivação na governamentalização da cidade. $O$ consumo de equipamentos de segurança, a fortificação dos condomínios e o movimento do rap aparecem como alguns dos efeitos dos afetos engendrados pela lógica neoliberal.
\end{abstract}

Palavras-chave: governamentalidade; afetos; cidade; cartografia; dispositivos de segurança.

\section{Governmentalization of the city: a cartography of affections, fear and hope}

\begin{abstract}
This paper presents a theoretical reflection on the city by considering the notion of governmentality. It aims to engender a cartography of affective lines by approaching newspaper reports, rap songs and private security advertisements. Fear and hope are two notions used to discuss about the ways of moving around the city and their relation with dispositifs of security. Fear, and specifically fear of death, constitutes an important mechanism of government, since, by constantly reminding subjects about their finitude, a wide security market emerges. Hope, on the other hand, is complementary to fear, and it is incited as a precarious strategy of joy, insofar as it constitutes itself as another form of suffering. An affection cartography provides clues of some modes of subjectivation in the governmentalization of the city. The consumption of security equipment, the fortification of condominiums and the rap movement emerge as some of the effects of the affections engendered by the neoliberal logic.
\end{abstract}

Keywords: governmentality; affections; city; cartography; dispositif of security.

Segundo Foucault (2008), a partir do problema de como governar as cidades no século XVII, possibilitou-se a emergência de uma modalidade complexa de poder que tem como objeto a população; como saber, a economia política; e, como principais instrumentos técnicos, os dispositivos de segurança. A isso ele denominou de governamentalidade. Para discutir essa modalidade de poder, aproximamo-nos aqui das discussões de Spinoza (2014), assim como das de Sennett (2010), Dunker (2015), Deleuze (1992) e Deleuze e Guattari (2011).

Se vivemos em uma era de governamentalidade, como Foucault (2008) afirma, quais afetos são suscitados na produção das subjetividades? Como a cidade contribui com esses processos de subjetivação? Realiza-se uma cartografia acompanhando o movimento de certos afetos traçados a partir de matérias jornalísticas sobre segurança e qualidade de vida, uma canção de rap sobre a cidade e uma publicidade do setor de segurança privada.

\footnotetext{
^Financiamento: CAPES e CNPq

$\star \star$ Endereço para correspondência: Universidade Federal de Mato Grosso do Sul - Reitoria, Campus de Paranaíba. Av. Pedro Pedrossian, no 725. Paranaíba, MS - Brasil. CEP: 79500000.E-mails: j.taborda7@gmail.com, anitabernardes1909@gmail.com. Os dados completos dos autores encontram-se ao final do artigo.
}

Segundo Deleuze e Parnet (1998, p. 43), nenhum enunciado é isolado, pois sempre é parte de um agenciamento: "O enunciado é o produto de um agenciamento, sempre coletivo, que põe em jogo, em nós e fora de nós, populações, multiplicidades, territórios, devires, afetos, acontecimentos". Cartografar é, portanto, acompanhar alguns movimentos por onde circulam os enunciados (matérias jornalísticas, canções de rap e publicidades) não como elementos abstratos e desconexos, mas como materialidades agenciadas, isto é, linhas heterogêneas com certo plano comum entre elas.

Os afetos do medo e da esperança apresentam-se como as ferramentas conceituais escolhidas para pensarmos a experiência atual de governamentalidade na cidade. Estas ferramentas afetivas podem ser aproximadas da ideia de intercessores, de Deleuze (1992), já que funcionam como corpos que não cessam de afetar campos distintos, seja a filosofia, a arte e a ciência, seja a segurança e a saúde. Entende-se que discutir os afetos que estão sendo agenciados por materialidades variadas pode tornar-se uma interessante estratégia para pensar a governamentalização da cidade. 
Para tanto, será preciso pensar os espaços da cidade não só como meros cenários onde os atores apenas circulam, mas também como potentes espaços de subjetivação que, conforme os afetos produzidos, conduzem diferentes variações nos modos de existir. O primeiro movimento desta cartografia, antes de tocar na questão dos afetos, passa a ser a problematização da cidade e de seus modos de circulação.

\section{Indo além dos problemas da cidade: a cidade como problema}

Muito se fala dos problemas da cidade: o trânsito difícil entre pedestres e motoristas, a falta de acessibilidade nas ruas, os alagamentos quando chove, os espaços pichados... Contudo, seria possível desnaturalizar a cidade e tomá-la como problema? E, se fosse, por onde começar uma problematização da cidade que leve em conta os afetos?

Tomando a cidade pela perspectiva rizomática de Deleuze e Guattari (2011), parte-se do pressuposto de que há uma multiplicidade de linhas com vários pontos de entrada possíveis para iniciar esta discussão. A entrada que aqui se escolhe para ingressar na temática da governamentalidade da cidade e seus afetos é a da circulação.

Conforme Sennett (2010), na Grécia Antiga (séc. V a. C.) e durante dois mil anos, o calor corporal foi a base da ciência médica que explicava as diferenças entre os corpos: o calor uterino produziria a virilidade dos machos, enquanto a falta deste calor produziria fêmeas frágeis. $\mathrm{O}$ esperma era entendido como um sangue fervente e pulsante de vida, ao passo que o sangue menstrual seria frio e inerte. Esta concepção de corpo era tão forte que até os modos de andar pela cidade tinham esta mesma base: o caminhar ereto e rígido seria próprio do homem nobre e viril, enquanto os passos lentos e tímidos seriam característicos das mulheres. O corpo e suas variações de temperatura eram a base que moldava a arquitetura da cidade e, consequentemente, afetava os modos de pensar e de agir.

Essa concepção corporal foi modificada radicalmente apenas em 1678 (séc. XVII), quando William Harvey publicou De motu cordis (SENNETT, 2010): ao estudar os mecanismos da circulação sanguínea, a noção de circulação desenvolvida por Harvey não apenas provocou uma revolução científica na medicina, como também afetou vários outros campos, como a economia, o urbanismo e a saúde pública. Foi a partir da noção de circulação de Harvey que Adam Smith pensou a circulação livre do mercado no capitalismo nascente; engenheiros e urbanistas passaram a construir espaços nas cidades objetivando garantir melhores formas de locomoção e circulação; e também foi graças à ideia de circulação aplicada à cidade que se começou a perceber a relação entre os espaços e a saúde pública (SENNETT, 2010). Pode-se dizer que a ideia de circulação trazida pelos estudos de Harvey, além de emergir como uma noção médica, surge como um potente conceito que ressoa e consegue articular o campo da economia, a arquitetura urbanística e a saúde dos citadinos, para citar alguns.

Fractal, Rev. Psicol., v. 32 - n. 2, p. 132-141, 2020
Foucault (2008), em seu curso Segurança, Território, População, também discute a circulação pelas cidades e até chega a mencionar o tema da circulação sanguínea. Ele cita o projeto de um arquiteto chamado Rousseau, que teve a ideia de reconstruir Nantes com o formato de coração, a fim de garantir melhores modos de circulação. Contudo, o filósofo passa rápido sobre o tema circulação-sangue, já que seu foco é a constituição dos instrumentos técnicos da governamentalidade, destacando-se o que ele nomeou de dispositivos de segurança. Estes dispositivos são constituídos por mecanismos complementares: os espaços de segurança, o tratamento do aleatório, a normalização específica da segurança e a correlação técnica entre segurança e população (FOUCAULT, 2008).

Conforme Foucault (2008), enquanto a construção de uma capital e a garantia de dominação de um território são um problema do poder soberano, no caso da cidade planejada, isto é, construída a partir de um espaço vazio, tem-se um típico problema do poder disciplinar. Para Foucault (2008), o problema da segurança emergirá quando se tornarem necessárias constantes reurbanizações, capazes de garantir a funcionalidade da cidade em relação a seu desenvolvimento. Aparecem, então: o tema da higiene (como desenvolver a circulação econômica da cidade garantindo que não haja circulação de doenças e de doentes?); a questão do comércio interior (como ligar o comércio local com mercadorias vindas de fora e como exportá-las?); e o problema da vigilância (como garantir que a abertura da cidade, agora sem muralhas, lide com sua exposição tanto ao comércio quanto a ladrões, vagabundos e estrangeiros?) - sem dúvida, o mais importante (FOUCAULT, 2008).

Foucault (2008) também diferencia o poder soberano, disciplinar e de segurança do seguinte modo: no poder de soberania, a liberdade não era uma questão dada, mas uma condição excepcional de uma pequena nobreza; já no poder disciplinar, eram os espaços vazios e artificiais que precisavam ser organizados a fim de extrair-se o máximo de suas potências; somente em uma era de segurança, a partir do século XVIII, busca-se dar conta dos problemas que emergem com as crescentes liberações. A questão não é mais se o sujeito tem ou não liberdade, mas como acessar a liberdade - e é na circulação que a liberdade e a cidade se tornam um problema das artes de governar.

Segundo Foucault (2008), a principal característica dos dispositivos de segurança é o trabalho a partir de dados já produzidos. É possível entender esta questão por meio do exemplo dos casos de vandalismo: certos espaços da cidade têm problemas muito específicos que precisam ser solucionados ou pelo menos minimizados; sabendo-se que ocorrem muitos crimes de vandalismo, é preciso quantificá-los. As informações existentes sobre a cidade formam um banco de dados que possibilita outro importante princípio dos dispositivos: os cálculos probabilísticos. Busca-se, dessa forma, maximizar os efeitos positivos ao mesmo tempo em que se minimizam os negativos. Tendo-se a informação de que ocorrem mais crimes de vandalismo em certos lugares do que em outros, pode-se sugerir a instalação de câmeras de vigilância em 
espaços onde há maior probabilidade de que os crimes ocorram. Por outro lado, Foucault (2008) menciona que é preciso igualmente justificar a polifuncionalidade dessas tecnologias: as câmeras não servem apenas para detectar os crimes de vandalismo, mas também para identificar suspeitos ou foragidos, coibir condições de estupro e, por que não, identificar protestos e manifestantes em nome da boa ordem da cidade. Além disso, é bastante significativa, nestes dispositivos, a ideia de futuro. Certos problemas da cidade são esperados, e, quando chegarem, já se saberá como agir. Com todos aqueles que ainda não ocorreram, será possível aprender, a fim de que no futuro causem menos transtornos (FOUCAULT, 2008).

Sendo a população o objeto da governamentalidade, a cidade e seus modos de circulação aparecem como uma potente máquina de subjetivação: "o olhar percorre as ruas como se fossem páginas escritas: a cidade diz tudo o que você deve pensar, faz você repetir o discurso [...]" (CALVINO, 2003, p. 20). Foucault (1996) concordaria com o poeta de As cidades invisíveis ao dizer que a circulação pela cidade não se faz de qualquer forma e em qualquer espaço, pois a vida da população governamentalizada se inscreve em certa ordem do discurso que faz ver e que faz falar. Na correlação entre poder e desejo, certos afetos passam a ser mais valorizados do que outros.

A pesquisa de Taborda (2017) também questiona a aparente neutralidade dos muros, as arquiteturas silenciosas e os sedutores outdoors, ao cartografar o uso dos espaços mediante a prática da pichação. Os afetos suscitados por esta prática nos mais variados espaços da cidade podem e devem ser problematizados, já que cada microlugar da cidade possui suas regras e modos de circulação. Esta correlação de forças entre práticas subversivas e regras instituídas ocorre em inúmeros espaços, sejam eles públicos ou privados, mas é na vida pública que os afetos desses processos de subjetivação podem ganhar maior visibilidade (TABORDA, 2017). Se cada vez mais os espaços públicos se deterioram devido à privatização dos modos de circulação, outros usos tornam-se possíveis.

A decadência da vida pública é indagada por Sennett (1988) a partir de um acontecimento muito comum nas cidades: o encontro com estranhos é cada vez mais visto como uma ameaça. É preciso, então, retomar os questionamentos que iniciaram este trabalho: como os espaços da cidade atuam nos processos de subjetivação? Quais afetos são mais incitados nos modos de circulação?

\section{A linha-afeto ou o uso dos afetos em Spinoza}

Para Spinoza (2014), o encontro não é um evento do dia a dia - ele constitui a própria existência: na relação do encontro entre o ar e os pulmões é produzido o oxigênio essencial à vida; na relação entre a luz e os olhos é produzida a capacidade de visão; e até as palavras que são lidas neste exato momento são produto de certo encontro. "Tudo no mundo começou com um sim. Uma molécula disse sim a outra molécula e nasceu a vida" (LISPECTOR, 1998, p. 11). Para Clarice Lispector, uma leitora de Spinoza, assim como para o filósofo que a inspirou, o encontro entre duas pessoas é apenas uma relação entre uma multiplicidade de outras relações.

E se a cidade não é apenas um meio inócuo, mas são justamente os modos de circulação a própria condição de existência, também é possível que cada encontro entre o sujeito e a cidade seja singular, ambos se diferenciando e variando sua potência de existir. Um dos efeitos do encontro com a cidade é a produção de afetos singulares, a produção de diferenças, e não de mesmices.

Os encontros podem ter apenas dois desfechos, segundo Spinoza (2014): bons encontros ou maus encontros. Entendendo os corpos como elementos singulares que se distinguem pela relação de movimento e de repouso, caso se trate de um bom encontro, isso significa que houve uma relação que compôs com o corpo afetado, então, isso produz o afeto que ele chama de alegria (passagem a uma maior perfeição); caso contrário, se o encontro não compõe, isso significa que ele decompõe o corpo, e, por ser um mau encontro, isso produz o afeto de tristeza (passagem a uma menor perfeição). Essa variação contínua aumento-diminuição-aumento-diminuição entre alegrias e tristezas constitui a condição do existir ou, nos dizeres de Spinoza, constitui a própria potência de agir (SPINOZA, 2014).

Contudo, para não cair em um reducionismo relativista no qual tudo se resumiria a modos de percepção, é preciso destacar a concretude e o viés ético-político na relação entre os afetos e a cidade. Segundo Foucault (2008), quando os fenômenos passam a ser geridos e esperados pela sociedade de segurança, eles perdem o caráter acidental para entrar no campo do probabilístico, o que forja certa naturalização de fenômenos que se repetem. Se entendermos que as desigualdades sociais e outros fenômenos foram se tornando mais e mais naturalizados, não se trata apenas de uma percepção positiva ou negativa, mas de que as cidades podem tornar-se máquinas reais de entristecimento e de produção de maus encontros. Moradia indigna, transporte público precário e caro, ruas sem asfalto... Não são apenas modos de percepção; os discursos não estão inscritos na "cabeça" das pessoas, mas na carne de cada citadino que compõe a população.

Além dos afetos de alegria e de tristeza já mencionados, para problematizar o uso dos afetos nas questões da cidade será preciso incluir o afeto de desejo, o terceiro afeto básico, do qual derivam todos os outros. Conforme Spinoza (2014), o desejo é sempre efeito dos encontros: primeiro, de modo inconsciente, um bom encontro adquire a forma de apetite; depois, quando se tem a consciência desse apetite, este passa a ser chamado de desejo. O desejo ou vontade seria, assim, a própria essência dos sujeitos, pois se trata do esforço de conservar sua potência de existir (SPINOZA, 2014). Tal esforço está sempre em variação contínua a cada novo encontro com outros corpos.

A vontade de verdade foucaultiana pode ser aproximada aqui das noções spinozistas de vontade e de desejo. Foucault (1996) dirá que, dos três grandes modos de exclusão que atingem o discurso, além da palavra proibida 
e da segregação da loucura, é da vontade de verdade que menos se fala. E, do mesmo modo que não se diz nada que não esteja na ordem do discurso, não se circula pela cidade de qualquer forma, já que existem certas regras e modos de funcionamento que garantem a segurança dos espaços.

Foi pensando nos jogos de verdade implícitos nos modos de circulação pela cidade que se chegou ao afeto do medo como efeito da produção de certos discursos e capaz de fornecer algumas pistas sobre esses processos.

\section{Circulando pela cidade e a gestão do medo}

Após discutir sobre os modos de circulação pela cidade e os três afetos básicos de Spinoza, é possível perguntar, como Sennett (1988): por que é que neste mundo de estranhos, que é a vida nas cidades, se torna possível que os encontros sejam percebidos como ameaças? Quais afetos a vida urbana atual vem suscitando?

Para Safatle (2016), a vida em sociedade organiza-se como um circuito de afetos, mas certa racionalidade condominial vem marcando de modo profundo as atuais relações sociais. As transformações políticas estão diretamente implicadas nos afetos que as constituem, e, dentre todos os afetos, é o medo que historicamente se faz mais presente nos vínculos sociais (SAFATLE, 2016). Conforme o autor, já no pensamento hobbesiano, que inaugura a filosofia política, o afeto que vem mobilizando a criação das mais variadas instituições no Ocidente é o medo: medo da perda, medo da despossessão dos bens, medo da morte violenta.

A inspiração de Safatle vem da tese de Dunker (2015, p. 42), que problematiza a chamada lógica do condomínio: "Chamo de lógica do condomínio a transformação dos problemas relativos à saúde pública, mental e geral, em meros problemas de gestão". A racionalidade higienista e militar que os modernos condomínios ostentam teria, conforme o autor, sua proveniência nos grandes hospitais psiquiátricos do século XIX. De acordo com Dunker (2015), essa lógica condominial aparece como um sintoma da modernidade brasileira. Contudo, diferentemente da leitura lacaniana desses autores, essa questão será aqui abordada pela perspectiva cartográfica dos afetos.

Spinoza (2014, p. 144), já em 1677, assim definia este afeto: "O medo é uma tristeza instável, surgida da ideia de uma coisa futura ou passada, de cuja realização temos alguma dúvida". O medo seria uma variação da potência de existir no sentido de perda de potência e, portanto, estaria associado à tristeza.

Matérias jornalísticas veiculadas cotidianamente podem auxiliar a pensar a produção desse afeto e a experiência de circulação nas cidades:

A violência é o principal item que puxa para baixo o desempenho do Brasil em qualidade de vida, dos 132 países analisados, de acordo com dados do relatório produzido pela organização sem fins lucrativos Social Progress Imperative. De acordo com o Mapa da Violência 2014, elaborado pela Faculdade Latino-americana de Ciências Sociais (Flacso), o Brasil tem uma taxa de 29 homicídios por 100 mil habitantes. Para conter esses números, também tem crescido a busca por equipamentos e soluções em segurança. Segundo a Associa- ção das Indústrias de Segurança no Brasil (SIA), o setor cresce, em média, 20\% ao ano. A previsão é que, até 2016, R $\$ 1,8$ bilhão movimente o setor (MERCADO..., 2015).

Dados mais recentes publicados pela OMS (Organização Mundial da Saúde) apontam que, no ano de 2018, o país ficou em nono lugar entre os países mais violentos do mundo (BRASIL..., 2018).

Ao invés de tomar as notícias apenas como retratos da violência cotidiana, elas podem servir como pistas dos modos de produção de discursos de verdade que articulam a circulação pela cidade com o afeto do medo. Como é comum encontrar nessas e em outras materialidades o discurso da segurança colado ao campo da saúde - nesse caso, como qualidade de vida -, convêm algumas observações sobre essa aproximação.

Se, conforme Spinoza (2014), cada encontro provoca uma variação na potência de existir, o aumento da potência dos bons encontros pode ser associado ao ganho de saúde, enquanto os maus, à sua perda. Como nenhum corpo busca a tristeza ou diminuição de potência, mas, ao contrário, sempre se esforça por aumentar sua potência de existir (SPINOZA, 2014), o afeto produzido no encontro com esses discursos de verdade tenderá a ser o medo. Deve-se a isso que, para a filosofia spinozana, basta imaginar a perda da potência para que o temor a faça diminuir.

Como a queda da qualidade de vida é o principal argumento de inúmeras matérias do gênero, o primeiro movimento passa a ser o questionamento dessa noção. Em vez de definir e tentar responder "o que é qualidade de vida", para a cartografia proposta por Deleuze e Guattari (2011) torna-se mais importante o modo de colocar o problema: quais condições tornam possível articular a noção de qualidade de vida a questões de segurança? Ou, dito de outra forma, o que torna possível a aproximação entre o campo da saúde e o campo da segurança, já que tal relação nem de longe é natural?

Conforme Minayo, Hartz e Buss (2000), a ideia de qualidade de vida esteve presente desde o nascimento da medicina social, no século XVIII, mas só se consolidou em fins do século XX, quando passou a ser articulada ao campo econômico e da saúde. Por mais vaga e imprecisa que seja essa noção, é justamente sua capacidade polissêmica que possibilita forjar inúmeros instrumentos, como o Índice de Desenvolvimento Humano (IDH), o Índice de Condições de Vida (ICV) e o Índice de Qualidade de Vida, capazes de articular questões econômicas, sociais, sanitárias e políticas (MINAYO; HARTZ; BUSS, 2000).

Articulando-se a noção de governamentalidade com a dinâmica dos afetos, pode-se chegar à seguinte questão: se, para Foucault (2008), a governamentalidade dita os discursos de verdade e naturaliza os modos de circulação pela cidade, para Spinoza (2014), ao imaginar-se o medo da perda da qualidade de vida, acredita-se que ele possa ser minimizado com a aquisição de equipamentos de segurança. Talvez seja essa uma das razões para a constante aproximação entre qualidade de vida e o tema da segurança. 
Um verbete disponível no Núcleo de Sociabilidade Libertária (NU-SOL) problematiza o tema da segurança ao definir qualidade de vida assim: "termo volátil, com pretensões a ser elevado a estatuto de conceito. Seu uso articula saúde, propriedade, educação, segurança, vida e morte. Constitui-se, atualmente na sociedade de controle, em um produto-marketing" (QUALIDADE DE VIDA, 2020). Por sua capacidade genérica, plástica e vaga, a qualidade de vida torna-se extremamente útil como agregador de valor econômico aos produtos, como se viu na matéria acima. Percebe-se que, tanto na referida matéria quanto na literatura especializada, é a imprecisão da qualidade de vida a resposta para o laço que une saúde e segurança.

Além da noção de qualidade de vida, destaca-se, em matérias desse tipo, o uso excessivo de cifras. "A linguagem numérica do controle é feita de cifras, que marcam o acesso à informação, ou a rejeição. [...] Os indivíduos tornaram-se 'dividuais', divisíveis, e as massas tornaram-se amostras, dados, mercados ou 'bancos"” (DELEUZE, 1992, p. 222). O abuso recorrente das cifras não é casual, pois se trata de um discurso de verdade sustentado pela estatística, saber privilegiado da governamentalidade (FOUCAULT, 2008). $\mathrm{O}$ discurso sobre a qualidade de vida evidencia e põe em debate a necessidade urgente de se adquirir uma ampla variedade de equipamentos de segurança. $\mathrm{O}$ afeto que faz variar a potência de existir e que atravessa esses discursos é o medo, pois já não se trata de conservar apenas o bem-estar ou a saúde, mas a própria vida.

Ao mesmo tempo em que os dispositivos de segurança, como efeitos da governamentalidade, produzem os discursos de verdade sobre a qualidade de vida e a circulação pela cidade, é possível problematizar outro efeito desse processo: os mecanismos de anulação (FOUCAULT, 2008). Segundo Foucault (2008), a produção constante de massas estatísticas sobre determinados fenômenos faz com que estes deixem de ser uma eventualidade para tornarem-se naturais e esperados. É a probabilidade de que ocorram novamente que produz o efeito de anular os fenômenos pelos próprios fenômenos. Tal mecânica também ajuda a explicar a aproximação naturalizada entre a segurança e a qualidade de vida. A produção dessa massa numérica só é possível graças a certas regras que cumprem determinadas funções no discurso (FOUCAULT, 1996). A estatística produz igualmente, pelo mecanismo de anulação, o apagamento da história de vida, dos contextos sociais, assim como da intensidade dos afetos em que ocorreu cada uma das mortes. Vidas singulares desaparecem entre cifras anônimas. O que importa na sociedade de controle é o número de anônimos habitantes, índices, taxas, relatórios e mais relatórios.

A incerteza, marca do afeto do medo, também pode encontrar nessas mortes anônimas outro reforçador. Se muitos morrem, o que garante que eu não serei o próximo, ou pior, minha família? Quantos anônimos e potenciais causadores dessas mortes não estão à solta nesta cidade? $\mathrm{O}$ que garante que eles também não rondam a minha vizinhança? Como controlar o que está além dos meus muros? Atentos a essa demanda de medrosos cidadãos, políticos profissionais içam a bandeira da seguran- ça pública, licitando empresas de segurança privada, que passam a instalar câmeras e redes de monitoramento para que a polícia vigie pontos estratégicos da cidade onde o capital possa circular livremente.

Como boa parte da classe média encontra-se na penumbra, nos pontos cegos a que o panóptico ainda não conseguiu chegar, ela se vê obrigada a contratar vigilantes noturnos particulares, a instalar cercas elétricas, a erguer seus muros e a adquirir recursos tecnológicos de menor qualidade, como interfones e câmeras pirateadas. É preciso lembrar que, assim como é anônimo o inimigo que ronda a vizinhança, os equipamentos de segurança adquiridos também são produzidos por trabalhadores igualmente anônimos. A maquinaria do medo engendrada por todos esses discursos de verdade rapidamente tornou os condomínios não apenas uma questão de necessidade, mas um estilo de vida (DUNKER, 2015). Uma cultura do medo é então fabricada com a ideia de que é preciso ter os equipamentos certos para exorcizar os perigos e a morte.

E como a morte poderia ser articulada à dinâmica dos afetos? Em vez de apenas trazer uma definição do que seja a morte para Spinoza, talvez seja mais interessante fazer uma breve cartografia dessa noção. Para tanto, é importante destacar que, para Spinoza (2014), a alegria e a tristeza não são emoções fugazes ou simples estados de ânimo. O afeto de alegria é um ganho de potência no nível da própria vida, assim como a tristeza é perda de potência também em relação à própria existência. Se viver está diretamente associado com a capacidade de o corpo ser afetado, a morte é justamente a ausência de afetos: "[...] compreendo que a morte do corpo sobrevém quando suas partes se dispõem de uma maneira tal que adquirem, entre si, outra proporção entre movimento e repouso" (SPINOZA, 2014, p. 183). Enquanto os encontros alegres são as condições de possibilidade para a ampliação da capacidade de viver, os encontros tristes, por sua vez, são as rupturas destas linhas. Sendo assim, a relação entre vida e morte precisa ser entendia como parte de um continuum entre alegrias e tristezas, respectivamente. A grande questão é que, na morte, há um sufocamento completo da existência e todas as linhas são rompidas.

Além disso, na perspectiva deste autor, uma explicação sobre a morte fica incompleta caso não esteja articulada ao maior objeto de suas meditações: a relação entre a escravidão e a liberdade. Em sua proposição de $n^{\circ} 67$ isso fica mais evidente: "Não há nada em que o homem livre pense menos que na morte, e sua sabedoria não consiste na meditação da morte, mas da vida." $\mathrm{E}$ continua em sua demonstração: "O homem livre, isto é, aquele que vive exclusivamente segundo o ditame da razão, não se conduz pelo medo da morte" (SPINOZA, 2014 , p. 200). Uma questão fundamental nesta articulação entre escravidão e liberdade é, portanto, o medo da morte. A produção do medo (lembrando que este afeto é também uma forma de tristeza) constitui um importante mecanismo de governo, pois, ao lembrar constantemente os sujeitos sobre sua finitude, um amplo mercado de segurança emerge como estratégia de manutenção de 
linhas alegres. Dito de outro modo, a sensação de insegurança que atravessa os mais variados enunciados na contemporaneidade é ao mesmo tempo meio e fim de um discurso mais complexo: o medo da morte.

Essa cartografia entre a tristeza e a morte pode ser interessante para pensar mais uma vez a relação entre a cidade e o campo da saúde:

Es esencial que se realice una evaluación sistemática del impacto que los cambios del medio ambiente producen en la salud, particularmente en los sectores de la tecnología, el trabajo, la energía, la producción y el urbanismo. Dicha evaluación debe ir acompañada de medidas que garanticen el carácter positivo de los efectos de esos cambios en la salud pública. La protección tanto de los ambientes naturales como de los artificiales, y la conservación de los recursos naturales, debe formar parte de las prioridades de todas las estrategias de promoción de la salud (BRASIL, 1986, p. 3-4, grifos nossos).

Esse trecho da Carta de Ottawa (BRASIL, 1986), que inaugurou a noção de promoção da saúde, insere pela primeira vez a ideia de que as políticas sanitárias não podem ser pensadas de forma abstrata, sem considerar os modos de circulação dos espaços e toda a geografia política da cidade. Se lembrarmo-nos das condições estruturais com que a maioria da população pobre necessita conviver - seja o saneamento básico, as ruas sem asfalto, moradias precárias ou praças descuidadas -, é possível afirmar que tais espaços não somente agenciam uma constante produção de tristezas, como também possibilitam a decomposição dos corpos dos sujeitos singulares. Dito de outro modo, em tais condições insalubres, os espaços da cidade podem ser transformados em máquinas de produção de morte.

Como cartografar é trabalhar com a abertura de linhas em movimento e fazer proliferar multiplicidades (DELEUZE; GUATTARI, 2011), seguir essas linhas traçadas pela tristeza e morte produzidas nos espaços urbanos tornou possível chegar a uma conexão bastante singular: as canções de rap. Em vez de uma simples representação dos anseios de uma parte da cidade periférica, as letras de rap podem ser articuladas à governamentalidade para pensar os afetos que atravessam a cidade como um todo.

Conforme Oliveira (2015), a música, assim como os demais movimentos artísticos, constitui-se em importante documento de uma época. Partindo-se da noção de intercessores, torna-se possível problematizar a relação da cidade com os afetos produzidos a partir de canções de rap. A leitura de Rap e Política: percepções da vida social brasileira (OLIVEIRA, 2015) possibilitou que se chegasse até este trecho da canção A cidade é nossa, composta pelo grupo Facção Central:

Circuito interno de TV, guarita; / Em vez de escola na periferia; / Alarme última geração na casa; / Em vez do barraco ter uma cesta básica; / Carro blindado, lataria anti-tiro; / Em vez de um curso no presídio; / A faca na sua garganta é o resultado; / Do seu dinheiro investido no lugar errado (MACAÉ-RJ; EDUARDO; DUM-DUM, 1999).
Como experiência política, Oliveira (2015) afirma que os afetos presentes nas letras de rap expressam as questões sociais e econômicas da vida dos marginalizados. Não é por acaso que esse movimento e a expansão da lógica condominial aparecem, ambos, na década de 1990, período da consolidação do neoliberalismo (DUNKER, 2015; OLIVEIRA, 2015). Os efeitos desse modelo econômico, que visa, entre outras medidas, ao fortalecimento do mercado em detrimento das políticas sociais, foram sentidos principalmente pela parcela pobre que vive nas periferias. Por outro lado, a lógica condominial visa a excluir ou pelo menos distanciar as classes abastadas do principal público do rap, isto é, dos moradores pobres da cidade. Para Dunker (2015), essa lógica não está circunscrita aos modernos condomínios, sendo um fenômeno que abarca também, mesmo que de modo distinto, as favelas e as prisões.

É preciso atentar para o fato de que, tanto na canção A cidade é nossa, cujo título é significativo, quanto em muitas outras letras de rap, a valorização da figura do ladrão como uma espécie de anti-herói tende a ser articulada com outro uso do medo. Se "cada cidade recebe a forma do deserto a que se opõe", como afirma Calvino (2003), o campo da arte torna possíveis outros usos dos afetos, e a noção de intercessores pode ajudar a problematizar essas ressonâncias.

Em entrevista com Gilles Deleuze, Foucault (1979) menciona que as massas não necessitam dos intelectuais para saber e para dizer; elas sabem e o dizem muito bem. Da mesma maneira que é indigno falar pelos outros (FOUCAULT, 1979), podem-se compreender as canções de rap não só de modo representativo, apenas como expressão de um sujeito que fala em nome de outros sem voz. Antes, é possível que a intensidade contida nas letras dos rappers seja um tipo de voz que se ouve e que causa afetos incômodos justamente porque diz respeito não somente a uma parcela da cidade, mas à vida urbana em geral. Por outro lado, mesmo falando da cidade de forma global, talvez sua menor contribuição seja o cunho revolucionário que algumas letras suscitam. Parecem ser mais relevantes, nesses discursos transgressivos, os ataques pontuais, as transgressões, as sedes particulares do poder, a denúncia dos pequenos fascismos diários e a produção de tristezas.

O rap, como voz da cidade, emerge justamente na mesma época da expansão de uma lógica condominial que transforma tudo em problemas de gestão, produzindo dois efeitos distintos, mas complementares em relação ao modelo neoliberal (DUNKER, 2015; OLIVEIRA, 2015). Novas formas de sentir medo emergem quando as relações entre os pares se tornam mais competitivas; quando o emprego se torna instável; quando as políticas sociais são precarizadas para se ajustarem às regras de mercado; quando as facilidades de crédito culminam em um endividamento constante; quando instituições tradicionais, como casamento, família e escola, deixam de ser garantias eternas (DUNKER, 2015). 
Dispositivos de segurança, como a lógica condominial, emergem, então, como novo sintoma, uma espécie de gestão do medo, e fazem parecer natural a aproximação entre a noção de qualidade de vida e o campo da segurança. Tal como a cidade, o neoliberalismo também é rizomático com a capacidade de absorver essas demandas, fazendo com que os afetos entrem e mobilizem os circuitos econômicos.

Após esta breve discussão sobre medo, tristeza e morte, é possível que se pergunte: há ainda esperança para a cidade? Quais esperanças? Como, para Spinoza (2014), a esperança é outro afeto e, como tal, outra modalidade de sofrimento, convém discutir a relação desse afeto com os dispositivos de segurança e sua relação com a cidade.

\section{De qual esperança estamos falando?}

Apesar de todos os problemas econômicos que o país atravessa, é interessante notar como o mercado de segurança privada, diferentemente de muitos outros setores, cresce de forma progressiva. Esse fenômeno pode ajudar a entender que não só o medo é mobilizado a favor de consumo. Para a governamentalização da cidade, tão importante quanto o medo é a esperança.

Na contramão do cenário econômico nacional, o setor de sistemas eletrônicos de segurança - que envolve uma grande variedade de produtos e serviços, como fechaduras inteligentes, blindagem, câmeras de monitoramento, segurança patrimonial, transporte de valores e escolta - deve crescer $10 \%$ até o final de 2015, de acordo com a ABESE - Associação Brasileira de Empresas de Sistemas Eletrônicos de Segurança (NA CONTRAMÃO..., 2015, online).

Em reportagem mais recente (FERNANDES, 2020), consta que o mercado de segurança eletrônica faturou R\$ 7,17 bilhões somente em 2019. É muito interessante se perguntar como o mercado de segurança, que cresce em média $8 \%$ ao ano, se torna tão rentável enquanto inúmeros setores sofrem com a atual crise econômica.

Do mesmo modo que as empresas de segurança privada esperam lucros cada vez maiores, os moradores da cidade governamentalizada esperam defender-se com o que poderíamos chamar de equipamentos de esperança. $\mathrm{O}$ trocadilho com equipamentos de segurança serve para destacar que é o afeto de esperança que se encontra colado na aquisição desses produtos: "espero não ser assaltado", “espero não ser sequestrado", "espero não ser baleado"...

Diferentemente do uso vulgar, que concebe a esperança sempre como algo positivo, na perspectiva spinozista e que fundamenta a cartografia, a esperança constitui-se como uma modalidade de sofrimento: "Os afetos da esperança e do medo não existem sem a tristeza. Com efeito, o medo é [...] uma tristeza, e a esperança [...] não existe sem o medo (SPINOZA, 2014, p 188). Foi dito que a ideia central do medo se devia à instabilidade ou flutuação de ânimo, mas apenas isso não ajuda muito. Facilita mais dizer que tal instabilidade se deve ao fato de que o medo sempre vem acompanhado de seu afeto complementar, a esperança. Spinoza assim define este afeto: “A esperança é uma alegria instável, surgida de uma coisa futura ou passada, de cuja realização temos alguma dúvida" (SPINOZA,
2014, p. 143). O principal elemento para compreender a relação entre estes dois afetos é a dúvida. E é justamente esta aposta duvidosa no futuro que alimenta fortemente o discurso da insegurança que paira nas cidades.

Quando foi dito que é o medo o afeto que mais mobiliza a atual experiência nas cidades, deve-se ler, portanto, que a esperança também está sempre presente nesse enunciado. E, se o aumento da esperança é diretamente proporcional ao aumento do medo, vê-se como essa fórmula é extremamente interessante para diversos mercados, com destaque para o mercado da segurança privada.

Além dos já discutidos dispositivos de segurança (FOUCAULT, 2008) e da lógica do condomínio (DUNKER, 2015), outra noção interessante para esta cartografia dos afetos pode ser a noção de sociedade de controle. O constante crescimento do consumo de aparatos eletrônico-militares dispersos pela cidade pode ser aproximado do diagnóstico descrito por Deleuze (1992) de uma sociedade cujo controle se torna maciço e pulverizado nas mais variadas instâncias. O filósofo argumenta que em tais sociedades não é o espaço que se sobrepõe ao tempo, como nas sociedades disciplinares; há primazia do tempo sobre o espaço, tal como acontece com os monitoramentos em tempo real. Também as moedas físicas deixam de ser a referência-padrão para as trocas flutuantes: não é preciso ter dinheiro físico ou pagar à vista pelos itens de segurança; os bancos e as empresas de segurança privada facilitam a negociação. Por fim, nas sociedades de controle, não há mais sujeito confinado e encerrado entre paredes, mas o sujeito aberto e endividado: monitoramentos, carros blindados ou condomínios fechados nunca serão suficientes, pois o mercado da segurança continua inovando com itens melhores e mais eficazes.

Com o aumento do medo e da esperança, tudo o que se adquire pela segurança passa a ser enunciado como "uma questão de necessidade". Mesmo se a aquisição de tais equipamentos ocasionarem endividamentos e a privação de outros benefícios, comprá-los torna-se realmente uma questão de necessidade se formos seguir a lógica spinozana. Isso porque, para o filósofo, o livre-arbítrio é apenas uma ilusão, pois cada afeto-paixão possui a sua necessidade (SPINOZA, 2014). Assim, quem teme e espera garantir a qualidade de vida, sua e de sua família, não escolhe se quer ou não adquirir tais equipamentos compra-os como uma questão de necessidade.

Não muito longe, na verdade logo ao lado, em outras modalidades de condomínios, mas também compondo a cidade, encontra-se a temida periferia. Ao mesmo tempo em que serviços públicos precários e Organizações Não Governamentais tornam possíveis novas linhas em relação ao futuro da população pobre, Unidades de Polícia Pacificadora (UPP) revelam um cenário desolador, constituindo-se como dispositivos de segurança bastante distintos dos de regiões mais nobres da cidade.

Os rappers, atentos ao cenário social, atentos ao medo e à esperança que os dispositivos de segurança incitam, não querem apenas mostrar que a periferia faz parte da cidade, mas que a própria cidade é deles. "Segurança 
atrás dando proteção; / A Ferrari é do otário, a cidade é do ladrão; / Construa fortaleza com vigia, muro alto; / Que mesmo assim vou enfiar seu pit-bull no seu rabo" (MACAÉ-RJ; EDUARDO; DUM-DUM, 1999). Tiros, mortes e desigualdades, enfim, outros usos dos afetos e outros usos da linguagem, expressos em gírias e palavrões, denunciam as diferentes formas de violência, assim como as esperanças e medos presentes na sociedade de controle.

Porém, seria um grande equívoco pensar que esse cenário se encontra apenas nas cidades brasileiras, haja vista a mundialização do capital. É claro que há a questão das singularidades regionais, mas os efeitos da articulação esperança-medo não cessam de deixar rastros também nos países mais ricos do mundo. Bem longe das favelas brasileiras, tomando como ponto de partida a cidade de Columbine, nos Estados Unidos, o documentarista Michael Moore (TIROS..., 2002) demonstra como a facilidade em adquirir armas e munições nos Estados Unidos não garante uma maior tranquilidade aos habitantes. Justo o oposto - vive-se em permanente estado de tensão, alavancado por altos índices de mortalidade e tragédias por armas de fogo (TIROS..., 2002). O documentário de Moore também traz importantes provocações sobre a relação entre interesses econômicos e violências por armas de fogo. Os circuitos medo-esperança parecem ser os animadores dos debates entre os defensores do direito ao porte de arma e aqueles que querem sua proibição ou um controle maior.

A circulação desses afetos, ao mesmo tempo em que alavanca o mercado de segurança privada, traz a ideia de que a cidade se encontra em uma guerra civil na qual todos precisam defender-se de todos. Casas, escolas, assim como ruas e praças, passam a ser adornadas por câmeras e por cercas e muros altos, alterando, inclusive, a estética da cidade, que começa a ostentar um aspecto condominial. Apesar de sempre presentes, o que menos se pretende na sociedade de controle são repressões e coerções: mais sutil e muito mais comum é a gestão dos modos de circulação das liberdades. Uma população esperançosa será bem mais interessante para a governamentalidade.

Seguindo-se essas linhas que conectam cidades, qualidade de vida, medo-esperança, bem como os enunciados do rap e da lógica do condomínio, pode-se chegar à última materialidade que também vem a ser objeto de análise. Proveniente do campo da segurança privada, uma publicidade de um tipo de cerca de proteção, a cerca concertina, pode ajudar a pensar as questões apresentadas até aqui:

A concertina foi desenvolvida pelas forças armadas norte-americanas buscando uma barreira mais eficaz e aos poucos foi tomando conta do mercado da segurança no mundo. A cerca concertina se apresenta melhor que o arame farpado. Ao invés de pontos "espetantes", as cercas concertinas possuem pequenas lâminas cortantes e pontiagudas, que ferem com mais intensidade quem pretende invadir a propriedade (INSTALAÇÃO..., 2019).

Medo, esperança, qualidade de vida, neoliberalismo e lógica do condomínio parecem estar condensados nessa propaganda. As mesmas linhas também podem ser acom- panhadas nas letras de rap, nas matérias jornalísticas e em outros enunciados. Se isso é possível, é porque essas linhas atravessam a cidade e conectam pontos aparentemente incoerentes. A proveniência militar norte-americana dos equipamentos lembra que o neoliberalismo se encontra consolidado e em desenvolvimento nas empresas brasileiras. O discurso belicista denunciado por Moore (TIROS..., 2002) em solo estadunidense apresenta-se mais verde-amarelo do que nunca.

E a qualidade de vida? Conforme os estudos psicanalíticos de Dunker (2015), o que impera na vida condominial são a sobriedade e a artificialidade. Isso se deve, em grande parte, ao modelo militarizado do qual provêm esses equipamentos. Para o psicanalista, e também do ponto de vista dos afetos, as guaritas, as câmeras e os muros de defesa visam tanto a impedir a entrada de inimigos quanto a produzir uma forma de vida comum sem uma verdadeira comunidade.

\section{Considerações finais}

Conforme Sennett (1998), o declínio da sociabilidade na cidade está diretamente associado ao declínio da vida pública. Uma cartografia dos afetos pode ajudar a entender esse processo, que é expresso em letras de rap tanto quanto em propagandas de equipamentos de segurança.

Como engendrar o medo e a esperança é relativamente simples, bastando imaginar que o futuro é incerto e que os perigos estão em qualquer lugar, o setor de segurança privada é um dos mais beneficiados. Por outro lado, a governamentalização da cidade toma a forma de uma gestão do medo, instalando inúmeros dispositivos técnicos a fim de organizar os modos de circulação pela cidade. Com a consolidação do neoliberalismo, emerge uma nova relação com a cidade, o que permite várias leituras dessa experiência: seja como lógica do condomínio (DUNKER, 2015), seja como sociedade de controle (DELEUZE, 1992), seja como sociedade de segurança (FOUCAULT, 2008), as discussões sobre a cidade aparecem concomitantemente ao que é denunciado pelos rappers - e, em todas essas questões, é possível cartografar os afetos do medo e da esperança como mobilizadores de tais práticas.

Apesar de singulares, as materialidades escolhidas não se constituem como exceções nem possuem características especiais. Basta ligar a televisão, conectar-se à internet ou folhear um jornal para encontrar enunciados articulando qualidade de vida e segurança privada. Com a produção repetitiva dos mesmos afetos, conforme Safatle (2016), há a tendência de se produzirem as mesmas disposições de conduta. Os dispositivos de segurança, que vão desde muros e câmeras até estatísticas e notícias, emergem, assim, tanto como um efeito do uso dos afetos produzidos quanto como um efeito da cidade governamentalizada. Seria, então, necessário parafrasearmos Spinoza (2014) e perguntarmo-nos: o que pode a cidade? 


\section{Informações sobre os autores:}

Jeferson Camargo Taborda

\section{iD https://orcid.org/0000-0003-1564-3212}

\section{(9) http://lattes.cnpq.br/0631132223013537}

Possui graduação em Psicologia (Universidade Católica Dom Bosco, 2009), mestrado em Psicologia da Saúde (Universidade Católica Dom Bosco, 2012) e doutorado em Psicologia da Saúde (Universidade Católica Dom Bosco, 2017). Atualmente é professor do Curso de Psicologia da Universidade Federal de Mato Grosso do Sul - Campus de Paranaíba. Tem experiência na área de Psicologia Social e Psicologia da Saúde com ênfase nos seguintes temas: Saúde Coletiva; articulações entre corpo, cidade e arte; Direitos Humanos-Famílias e questões LGBTI+.

\section{Anita Guazzelli Bernardes \\ (iD) https://orcid.org/0000-0003-4742-6036 \\ http://lattes.cnpq.br/8451095176999131}

Possui graduação em Psicologia pela Universidade do Vale do Rio dos Sinos (1996), mestrado em Psicologia pela Pontifícia Universidade Católica do Rio Grande do Sul (2002) e doutorado em Psicologia pela Pontifícia Universidade Católica do Rio Grande do Sul (2006). Realizou estágio pósdoutoral no Centro de Estudos Sociais da Universidade de Coimbra, sob o acompanhamento do Professor João Arriscado Nunes Atualmente é professora do curso de Psicologia, professora e pesquisadora do Programa de Mestrado e Doutorado em Psicologia e do Programa de Mestrado e Doutorado em Desenvolvimento Local da Universidade Católica Dom Bosco. Foi coordenadora do Programa de Mestrado e Doutorado em Psicologia da Universidade Católica Dom Bosco no biênio 2018-2019. É coeditora da Revista Psicologia \& Sociedade. Foi coordenadora do GT da ANPEPP “Tecnologias, políticas de pesquisa e modos de subjetivação" entre 2014-2016. É parecerista de periódicos científicos nacionais e internacionais, membro de corpo editorial de periódicos nacionais, é parecerista ad hoc de agências de fomentos a pesquisa (CNPq, CAPES, FUNDECT, FAPEMIG). É bolsista produtividade (PQ2). Tem experiência na área de Psicologia Social e Saúde, com ênfase principalmente nos seguintes temas:políticas públicas, formas de subjetivação, psicologia e trabalho. A professora é cocoordenadora do grupo de pesquisa do $\mathrm{CNPq}$ ?Modelos históricos epistemológicos e produção de Saúde? (UCDB) e membro dos grupos de pesquisa: Estudos Culturais e Modos de Subjetivação e o Núcleo Epolitcs (UFRGS); Políticas públicas, inclusão e produção de sujeitos (UNISC), Terapia Ocupacional e Saúde Mental (UFSCAR). Atualmente coordena o projeto COOPBRAS (Edital CAPES) que envolve Brasil, Chile e México.

\section{Contribuições dos autores:}

Ambos os autores colaboraram ao longo do processo, desde a elaboração até a revisão final do manuscrito. Os autores aprovaram o manuscrito final para publicação.

\section{Como citar este artigo:}

\section{ABNT}

TABORDA, Jeferson Camargo; BERNARDES, Anita Guazzelli. Governamentalização da cidade: uma cartografia dos afetos, medo e esperança. Fractal: Revista de Psicologia, Niterói, v. 32, n. 2 , p. 132-141, maio/ago. 2020. https://doi.org/10.22409/1984-0292/ v32i2/5691

\section{APA}

Taborda, J. C., \& Bernardes, A. G. (2020, Maio/Agosto). Governamentalização da cidade: uma cartografia dos afetos, medo e esperança. Fractal: Revista de Psicologia, 32(2), 132-141. doi: https://doi.org/10.22409/1984-0292/v32i2/5691

\section{Copyright}

Copyright (c) 2020 Taborda, J. C., \& Bernardes, A. G. Este é um artigo em acesso aberto distribuído nos termos da Licença Creative Commons Atribuição que permite o uso irrestrito, a distribuição e reprodução em qualquer meio desde que o artigo original seja devidamente citado.

Copyright (C) 2020 Taborda, J. C., \& Bernardes, A. G. This is an Open Access article distributed under the terms of the Creative Commons Attribution License, which permits unrestricted use, distribution, and reproduction in any medium, provided the original article is properly cited.

\section{Referências}

BRASIL. Ministério da Saúde. Carta de Ottawa. PRIMEIRA CONFERÊNCIA INTERNACIONAL SOBRE PROMOÇÃO DE SAÚDE, 1986. Disponível em: http://bvsms.saude.gov.br/ bvs/publicacoes/carta_ottawa.pdf. Acesso em: 15 dez. 2015.

BRASIL é o $9^{\circ}$ país mais violento do mundo, segundo a OMS. R7 Cidades, 2018. Disponível em: https://noticias.r7.com/ cidades/brasil-e-o-9-pais-mais-violento-do-mundo-segundo-aoms-17052018. Acesso em: 7 jan. 2020

CALVINO, Ítalo. As cidades invisiveis. São Paulo: Folha de S. Paulo, 2003.

DELEUZE, Gilles. Conversações. Rio de Janeiro: Editora 34, 1992.

DELEUZE, Gilles; GUATTARI, Félix. Mil platôs: capitalismo e esquizofrenia. São Paulo: Editora 34, 2011. v. 1.

DELEUZE, Gilles; PARNET, Claire. Diálogos. São Paulo: Escuta, 1998.

DUNKER, Christian Ingo Lenz. Mal-estar, sofrimento $e$ sintoma: uma psicopatologia do Brasil entre muros. São Paulo: Boitempo, 2015.

FERNANDES, Adriana. Mercado de segurança eletrônica no Brasil faturou R\$ 7,17 bilhões em 2019 - Abese prevê crescimento de $12 \%$ em 2020. Segs, 2020. Disponível em: https://www.segs.com.br/info-ti/212346-mercado-deseguranca-eletronica-no-brasil-faturou-r-7-17-bilhoes-em2019-abese-preve-crescimento-de-12-em-2020. Acesso em: 6 fev. 2020.

FOUCAULT, Michel. Microfisica do poder. Rio de Janeiro: Graal, 1979.

FOUCAULT, Michel. A ordem do discurso: aula inaugural no Collège de France, pronunciada em 2 de dezembro de 1970. São Paulo: Graal, 1996.

FOUCAULT, Michel. Segurança, território, população: curso dado no Collège de France (1977-1978). São Paulo: Martins Fontes, 2008.

INSTALAÇÃO de cerca concertina em Uberlândia e região. Empresa Proteção Segurança Eletrônica. Uberlândia, Minas Gerais. Modificado em: 1 jun. 2019. Disponível em: http:// www.protecaoudi.com.br/concertina.html. Acesso em: 3 abr. 2020

LISPECTOR, Clarice. A hora da estrela. Rio de Janeiro: Rocco, 1998.

MACAÉ-RJ, Vanone Rapman; EDUARDO; DUM-DUM. A cidade é nossa (Facção Central). Versos Sangrentos, 1999, faixa 10. Disponível em: https:/www.vagalume.com.br/faccaocentral/a-cidade-e-nossa.html. Acesso em: 12 dez. 2015. 
MERCADO de segurança cresce $20 \%$ ao ano. Portal Hospitais Brasil. São Paulo, 2015. Disponível em: https:// portalhospitaisbrasil.com.br/mercado-de-seguranca-cresce-20ao-ano/. Acesso em: 3 abril. 2020.

MINAYO, Maria Cecília de Souza; HARTZ, Zulmira Maria de Araújo; BUSS, Paulo Marchiori. Qualidade de vida e saúde: um debate necessário. Ciência \& Saúde Coletiva, Rio de Janeiro, v. 5, n. 1, p. 7-18, 2000. https://doi.org/10.1590/S141381232000000100002

NA CONTRAMÃO da economia, setor de sistemas eletrônicos de segurança cresce com insegurança da população. Dino Divulgador de Notícias. São Paulo, 2015. Disponível em: https://www.dino.com.br/releases/na-contramao-da-economiasetor-de-sistemas-eletronicos-de-seguranca-cresce-cominseguranca-da-populacao-dino89075896131/pdf. Acesso em: 10 dez. 2015.

OLIVEIRA, Roberto Carmagos de. Rap e Política: percepções da vida social brasileira. São Paulo: Boitempo, 2015.

QUALIDADE DE VIDA. Núcleo de Sociabilidade Libertária - Programa de Estudos Pós-Graduados em Ciências Sociais. PUC-SP. Modificado em: 3 jun. 2020. Disponível em: https:// www.nu-sol.org/abolicionismo-libertario-verbetes/. Acesso em: 3 jun. 2020.

SAFATLE, Vladimir. A lógica do condomínio. Youtube. 30 ago. 2016. 48min49s. Disponível em: https://www.youtube.com/ watch?v=zWnD_FYo1sQ. Acesso em: 9 jan. 2016.

SENNETT, Richard. O declínio do homem público: as tiranias da intimidade. São Paulo: Companhia das Letras, 1988.

SENNETT, Richard. Carne e Pedra: o corpo e a cidade na civilização ocidental. Rio de Janeiro: BestBolso, 2010.

SPINOZA, Baruch. Ética. Belo Horizonte: Autêntica, 2014.

TABORDA, Jeferson Camargo. Uso dos espaços e uso dos afetos: cartografias da pichação para pensar as relações entre a cidade e a governamentalidade. Tese (Doutorado)-Programa de Pós-graduação em Psicologia da Universidade Católica Dom Bosco, Campo Grande, 2017. Disponível em: https://site.ucdb. $\mathrm{br} / /$ public/md-dissertacoes/1023422-1.pdf. Acesso em: 20 set. 2019.

TIROS em Columbine (Bowling for Columbine). Direção Michael Moore. Produção de Charles Bishop, Jim Czarnecki, Michael Donovan, Kathleen Glynn e Michael Moore. Roteiro: Michael Moore. EUA: Metro-Goldwyn-Mayer Distributing Corporation/ United Artists, 2002. 1 DVD (120 min), son., color. 